Power spect rum char act er i st i cs of body sway ti me series and vel ocity time series of the center of foot pressure during a static upright posture in preschool chi I dren

\begin{tabular}{|l|l|}
\hline 著者 & Demur a Shi ni chi , Ki t abayashi Tanmt su \\
\hline $\begin{array}{l}\text { j our nal or } \\
\text { publ i cat i on ti tl e }\end{array}$ & Sport Sci ences for Heal th \\
\hline vol une & 3 \\
\hline nunber & $1-2$ \\
\hline page r ange & $27-32$ \\
\hline year & 2008 - 01- 01 \\
\hline URL & ht t p: //hdl . handl e. net /2297/12046 \\
\hline
\end{tabular}


Original article

\section{Power spectrum characteristics of body sway time series and velocity time series of the center of foot pressure during a static upright posture in preschool children}

Running head: Power spectrum characteristics of body sway

$$
\text { SHINICHI DEMURA }{ }^{1)} \text {, and TAMOTSU KITABAYASHI }{ }^{2)}
$$

${ }^{1)}$ Kanazawa University, Graduate School of Natural Science \& Technology, Kakuma, Kanazawa, Ishikawa 920-1164, JAPAN.

${ }^{2)}$ Tokyo University of Science, 1-3 Kagurazaka, Shinjuku, Tokyo, 162-8601, JAPAN.

Please address correspondence to Tamotsu Kitabayashi, Faculty of Science, Tokyo University of Science, 1-3 Kagurazaka, Shinjuku, Tokyo, 162-8601, JAPAN. Tel: +81 $0859245060 \quad$ Fax: +810859245060 e-mail: kitatamo222@yahoo.co.jp 


\section{Abstract}

This study aimed to determine an individual difference and gender difference of power spectra in the body sway time series and sway velocity time series during a static upright standing posture using 30 preschool children and their spectrum distribution characteristics. The center of pressure (COP) movement for 1 min was measured twice with a 1 min rest. The measurement instrument used was an Anima's stabilometer G5500. The data sampling frequency was $20 \mathrm{~Hz}$. A power spectrum was calculated by applying a Fast Fourier Transform to time series data of $\mathrm{X}$ (Medial/Lateral) and Y (Anterior/Posterior) directions. The Coefficient of Variation (CV) over 10.0 of power was large from $0.06 \mathrm{~Hz}$ to $1.4 \mathrm{~Hz}$ in both directions, and as the frequency became higher, the $\mathrm{CV}$ became less. There were significant gender differences in the low frequency bands (less than $2.0 \mathrm{~Hz}$ ), and almost all power of body sway time series and velocity time series were found in the low frequency bands (A and B sections) of the international standard, and individual differences were also large. The distribution of power spectra of their time series was different in both directions. The present results suggest that the evaluation section of the existing international standard cannot properly evaluate periodic characteristics of body sway time series and sway velocity time series of preschool children.

Keywords: center of pressure, body sway, preschool children 


\section{Introduction}

Body sway during an upright standing posture has been evaluated using center of pressure (COP) sway. COP parameters evaluating mainly body sway size such as distance, area, and velocity have been used in previous studies [1-2]. However, recently, a great deal of attention has been paid to time-series characteristics of sway, in addition to sway size. In particular, an analysis of the power spectrum is considered to be very important because it can evaluate the sway periodicity differing from the sway size [3-4]. In the international standard, the frequency band of the power spectrum was divided into three sections; $0.02 \mathrm{~Hz} \sim 0.2 \mathrm{~Hz}, 0.2 \mathrm{~Hz} \sim 2 \mathrm{~Hz}$, and $2 \mathrm{~Hz} \sim 10 \mathrm{~Hz}$. And the body sway has been evaluated by relative comparisons among the power spectrum included in each of the three sections. Disordered people (e.g.; unilateral labyrinth disability: about $2 \mathrm{~Hz}$ in the X-direction, bilateral labyrinth disability: $0.6-0.8 \mathrm{~Hz}$ in the Y-direction, subfolium disability: $3 \mathrm{~Hz}$ ) show very high power spectra in the specific high frequency band. Hence, the above evaluation method has been considered to be useful for evaluating body sway characteristics of people with disequilibrium [5-6]. However, some researchers [7-9] reported that healthy people show body sway with extremely low frequencies during an upright posture, which relates little to posture control. Therefore, the international standard may be unable to properly evaluate time-series characteristics of their body-sway. Kitabayashi et al. [10] pointed out that power spectrum parameters in young adults have little relationship to parameters regarding sway-size and sway-velocity $(r<0.3)$, and are different in quality from the latter parameters.

Preschool-aged children are in a marked developmental stage for the posture adjustment function, and also functions of leg muscles, nerves and sense are undeveloped [11]. Hence, it may be difficult for preschool children to maintain a 
steady standing posture. Usui et al. [12] reported that for preschool children, because of undeveloped spine erector and antagonist muscles (abdominal muscle), their contribution to posture control is small, and their body-sway is larger than in young adults. Previous studies have examined preschool children's body sway characteristics mainly using sway-size parameters such as distance, velocity, and area. Few have examined time-series periodical characteristics of body sway. In addition, preschool children may have gender differences also in body sway, as revealed by physique and physical fitness [13].

This study aimed to determine an individual difference and gender difference of power spectra of body sway time series and sway velocity time series, and their spectrum distribution characteristics during a static upright posture of preschool children.

\section{Methods}

Subjects

The subjects were thirty healthy preschool children (15 boys, age: $4.2 \pm 1.27$ years, height: $104.5 \pm 2.57 \mathrm{~cm}$, weight: $14.1 \pm 2.26 \mathrm{~kg}, 15$ girls, age: $4.5 \pm 1.15$ years, height: $104.1 \pm 2.42 \mathrm{~cm}$, weight: $15.9 \pm 2.92 \mathrm{~kg}$ ). Before measurement, the purpose and procedure of this study were explained in detail to them and to their parents. Informed consent was obtained from all subjects and their parents. This experimental protocol was approved by the Ethics committee (Kanazawa University Health \&Science Ethics committee).

\section{Experimental procedures}

The measurement procedure followed the method prescribed in the standardization of the stabilometry test [14]. The subjects maintained a static upright posture with feet together (Romberg posture) for 1 min. During the testing, they were 
instructed to watch a circular target placed at eye level and stood bare-foot with their arms held comfortably and their eyes open. The measurements began after the subject's posture and eyes were stable. The test was performed twice, with a 1 min rest period. The second trial data was used for the analysis. We instructed subjects not to change the position of their feet on the plate during the rest period in a sitting position.

\section{Experimental instrument}

The measurement instrument used was a stabilometer G5500 (Anima, Japan). This instrument can calculate the COP of vertical loads from values of three vertical load sensors, which are located in the corners of an isosceles triangle on a level surface. The data sampling frequency was set at $20 \mathrm{~Hz}$.

\section{Evaluation parameters}

We performed a frequency analysis by applying Fast Fourier Transform (FFT) to center of pressure sway and sway velocity time-series data in the $\mathrm{X}$ (Medial/Lateral) and Y (Anterior/Posterior) directions, and calculated the power spectrum. Each individual's power spectrum was converted into relative values in each frequency section based on the total spectrum and was accumulated.

\section{Data Analysis}

Two-way ANOVA (frequency section $\times$ gender) was applied to examine the frequency sections and gender differences for accumulated relative values of the power spectrum. The coefficient of variation (CV) of each frequency section was calculated to examine the size of their individual differences. A probability level of 0.05 was considered as indicative of statistical significance. 


\section{Results}

Figure 1 shows power spectrum of body sway time series and velocity time series of the X-and Y- directions. A power spectrum of body sway time series appeared more under $0.2 \mathrm{~Hz}$ in both directions, and power over $2.0 \mathrm{~Hz}(\mathrm{C}: 2 \mathrm{~Hz}-10 \mathrm{~Hz}$ ) was $15 \%$ or less of a total power spectra. A power spectrum of body sway velocity time series appeared over $2.0 \mathrm{~Hz}$ in both directions. Namely, power spectra of body sway time series and velocity time series showed different distribution characteristics, and the latter appeared over a wider range.

****Figure 1 near here ${ }^{* * * *}$
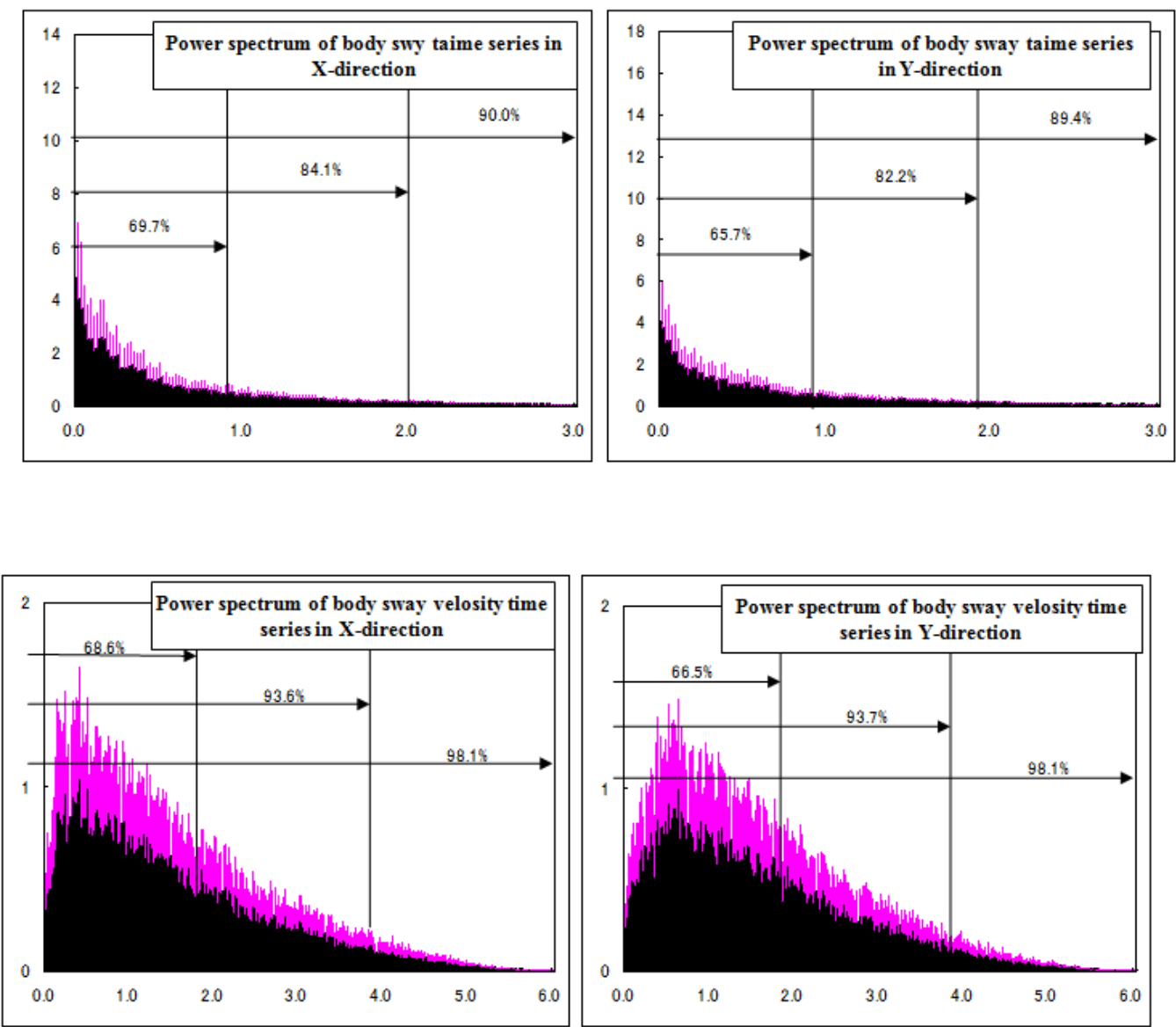

Figure 1 Power spectrums of body sway and sway velocity time series the $\mathrm{X}$-, Y-directions 
Tables 1, 2 show basic statistics and the results of two-way ANOVA for relative accumulated power spectra of body sway time series and velocity time series. The ANOVA results showed significant gender differences of both power spectra in both directions, and males were larger than females in the low frequency band. Frequency bands with a large CV over 10.0 appeared up to $1.0 \mathrm{~Hz}$ in the power spectra of sway time series and $1.5 \mathrm{~Hz}$ in the power spectra of sway velocity time series, and as the frequency became higher, the CV became less.

****Table 1 and 2 near here****

\begin{tabular}{|c|c|c|c|c|c|c|c|c|c|c|c|c|c|c|c|c|c|c|}
\hline \multirow[b]{2}{*}{ bands } & \multicolumn{9}{|c|}{ power spectrum of $X$-direction } & \multicolumn{9}{|c|}{ power spectrum of $Y$-direction } \\
\hline & \multicolumn{3}{|c|}{$\mathrm{SD}^{\text {all }}$} & \multicolumn{3}{|c|}{ 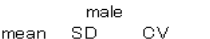 } & \multicolumn{3}{|c|}{$\begin{array}{l}\text { female } \\
\text { SD }\end{array}$} & \multicolumn{3}{|c|}{$\mathrm{SD}^{\text {all }}$} & \multicolumn{2}{|c|}{$\begin{array}{l}\text { male } \\
\text { mean } S D\end{array}$} & $\mathrm{cV}$ & \multicolumn{3}{|c|}{$\begin{array}{l}\text { female } \\
\mathrm{SD}\end{array}$} \\
\hline 0.06 & 12.6 & 5.8 & 46.0 & 14.3 & 6.0 & 41.6 & 10.8 & 5.2 & 48.2 & 10.9 & 4.6 & 42.1 & 12.2 & 5.3 & 43.2 & 9.5 & 3.4 & 36.0 \\
\hline 0.1 & 18.2 & 6.6 & 36.4 & 20.4 & 7.5 & 37.1 & 16.1 & 4.9 & 30.8 & 16.5 & 5.3 & & 18.3 & 5.9 & 32.2 & 14.8 & 4.2 & 28.4 \\
\hline 0.2 & 30.3 & 8.0 & 26.4 & 33.6 & 9.2 & 27.3 & 26.9 & 4.9 & 18.1 & 26.6 & 5.7 & 21.5 & 28.4 & 6.0 & 21.2 & 24.9 & 5.0 & 20.2 \\
\hline 0.3 & 39.4 & 8.5 & 21.5 & 42.9 & 9.5 & 22.2 & 35.9 & 5.6 & 15.5 & 34.6 & 5.6 & 16.1 & 36.3 & 6.1 & 17.0 & 33.0 & 4.6 & 13.8 \\
\hline 0.4 & 46.6 & 8.4 & 18.0 & 50.1 & 9.1 & 18.1 & 43.1 & 6.0 & 14.0 & 40.9 & 5.6 & 13.7 & 43.0 & 6.2 & 14.3 & 38.9 & 4.2 & 10.9 \\
\hline 0.5 & 53.4 & 8.6 & 16.1 & 57.0 & 8.8 & 15.5 & 49.8 & 6.8 & 13.7 & 47.6 & 5.7 & 12.1 & 49.6 & 6.2 & 12.4 & 45.6 & 4.7 & 10.3 \\
\hline 0.6 & 57.7 & 8.4 & 14.5 & 61.4 & 8.2 & 13.4 & 54.0 & 6.9 & 12.8 & 52.5 & 5.6 & 10.8 & 54.9 & 5.3 & 9.6 & 50.2 & 5.1 & 10.2 \\
\hline 0.7 & 61.3 & 8.4 & 13.7 & 65.1 & 7.7 & 11.8 & 57.5 & 7.5 & 13.0 & 56.8 & 5.7 & 10.1 & 59.2 & 4.9 & 8.2 & 54.4 & 5.7 & 10.4 \\
\hline 0.8 & 64.5 & 8.0 & 12.4 & 68.3 & 7.1 & 10.3 & 60.8 & 7.3 & 12.0 & 60.2 & 5.9 & 9.8 & 62.8 & 5.1 & 8.2 & 57.7 & 5.7 & 9.8 \\
\hline 0.9 & 67.3 & 7.4 & 10.9 & 70.9 & 6.3 & 8.9 & 63.7 & 6.7 & 10.5 & 63.0 & 6.0 & 9.5 & 65.4 & 5.5 & 8.4 & 60.6 & 5.6 & 9.2 \\
\hline 1.0 & 69.7 & 6.7 & 9.7 & 73.1 & 5.6 & 7.7 & 66.4 & 6.2 & 9.3 & 65.7 & 5.9 & 9.0 & 68.0 & 5.5 & 8.1 & 63.4 & 5.5 & 8.7 \\
\hline 1.2 & 73.9 & 5.7 & 7.8 & 76.9 & 4.8 & 6.3 & 70.8 & 4.9 & 7.0 & 70.2 & 5.7 & 8.2 & 72.2 & 5.3 & 7.3 & 68.1 & 5.6 & 8.1 \\
\hline 1.4 & 77.5 & 4.8 & 6.2 & 80.0 & 4.2 & 5.2 & 74.9 & 4.0 & 5.3 & 74.1 & 5.3 & 7.2 & 75.9 & 4.9 & 6.5 & 72.3 & 5.3 & 7.4 \\
\hline 1.6 & 80.1 & 4.3 & 5.3 & 82.2 & 3.8 & 4.6 & 78.0 & 3.6 & 4.7 & 77.2 & 5.1 & 6.6 & 78.7 & 4.9 & 6.2 & 75.7 & 5.0 & 6.6 \\
\hline 1.8 & 82.1 & 4.0 & 4.9 & 84.1 & 3.6 & 4.3 & 80.2 & 3.5 & 4.4 & 79.8 & 4.7 & 5.9 & 31.1 & 4.4 & 5.5 & 78.5 & 4.7 & 6.0 \\
\hline 2.0 & 84.1 & 3.7 & 4.4 & 85.8 & 3.2 & 3.7 & 82.3 & 3.4 & 4.1 & 82.2 & 4.5 & 5.5 & 83.3 & 4.3 & 5.1 & 81.1 & 4.6 & 5.6 \\
\hline 2.5 & 87.5 & 3.1 & 3.6 & 89.0 & 2.7 & 3.0 & 86.1 & 2.9 & 3.4 & 86.3 & 4.1 & 4.8 & 87.3 & 3.6 & 4.1 & 85.4 & 4.5 & 5.3 \\
\hline 3.0 & 90.0 & 2.8 & 3.1 & 91.3 & -22 & 24 & 88.8 & 2.8 & 3.2 & 89.4 & 3.7 & 4.1 & 901 & 3.2 & -3.6 & 88.7 & 4.0 & 4.5 \\
\hline 3.5 & $\overline{91} \overline{9}$ & 2.5 & $2 . \overline{7}$ & $\overline{92.9}$ & 2.0 & 2.1 & 90.9 & 2.5 & 2.8 & 91.6 & 3.3 & 3.7 & 92.1 & 2.9 & 3.2 & 91.1 & 3.7 & 4.1 \\
\hline 4.0 & 93.5 & 2.1 & 2.3 & 94.3 & 1.8 & 1.9 & 92.6 & 2.2 & 2.4 & 93.3 & 3.0 & 3.3 & 93.7 & 2.7 & 2.9 & 93.0 & 3.4 & 3.7 \\
\hline 4.5 & 94.6 & 1.9 & 2.0 & 95.3 & 1.6 & 1.7 & 94.0 & 1.9 & 2.1 & 94.6 & 2.7 & 2.9 & 94.9 & 2.3 & 2.5 & 94.3 & 3.1 & 3.3 \\
\hline 5.0 & 95.7 & 1.7 & 1.8 & 96.2 & 1.5 & 1.6 & 95.1 & 1.8 & 1.8 & 95.7 & 2.5 & 2.6 & 95.9 & 2.2 & 2.2 & 95.5 & 2.9 & 3.0 \\
\hline 5.5 & 96.5 & 1.6 & 1.6 & 96.9 & 1.4 & 1.4 & 96.1 & 1.7 & 1.7 & 96.6 & 2.3 & 2.4 & 96.7 & 2.0 & 2.1 & 96.5 & 2.7 & 2.8 \\
\hline 6.0 & 97.2 & 1.4 & 1.5 & 97.5 & 1.3 & 1.3 & 96.8 & 1.5 & 1.6 & 97.2 & 2.1 & 2.2 & 97.3 & $\begin{array}{l}1.8 \\
\end{array}$ & 1.9 & 97.2 & 2.4 & 2.5 \\
\hline & & & & & F-value & & & $*$ & & & & & & F-value & & & & \\
\hline ANOVA & & sectio & diff & & F-value & $=1764$. & & * & & & sectio & & & F-value & $=2448.3$ & & * & \\
\hline & & & & & -value & $=4.25$ & & * & & & intera & 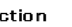 & & $\mathrm{F}$-value & $=2.40$ & & * & \\
\hline
\end{tabular}

\begin{tabular}{|c|c|c|c|c|c|c|c|c|c|c|c|c|c|c|c|c|c|c|}
\hline \multirow[b]{2}{*}{ bands } & \multicolumn{9}{|c|}{ power spectrum of $X$-direction } & \multicolumn{9}{|c|}{ power spectrum of $Y$-direction } \\
\hline & mean & $D^{\text {all }}$ & $\mathrm{OV}$ & mean & $\begin{array}{l}\text { male } \\
S D\end{array}$ & ov & & $\begin{array}{l}\text { female } \\
S D\end{array}$ & ov & & $\mathrm{SD}^{\text {all }}$ & $\mathrm{CV}$ & mean & $\begin{array}{l}\text { male } \\
S D\end{array}$ & cV & & $\begin{array}{l}\text { female } \\
\text { SD }\end{array}$ & $\mathrm{CV}$ \\
\hline 0.06 & 1.0 & 0.5 & 50.4 & 1.2 & 0.6 & 48.7 & 0.8 & 0.3 & 39.0 & 0.7 & 0.3 & 44.7 & 0.8 & 0.3 & 39.4 & 0.6 & 0.3 & 48.8 \\
\hline 0.1 & 1.9 & 0.8 & 43.0 & 2.2 & 1.0 & 44.1 & 1.5 & 0.4 & 23.7 & 1.5 & 0.6 & 37.0 & 1.7 & 0.6 & 36.9 & 1.3 & 0.4 & 30.4 \\
\hline 0.2 & 5.4 & 2.3 & 43.6 & 6.3 & 2.8 & 43.9 & 4.4 & 1.3 & 29.0 & 4.0 & 1.1 & 28.0 & 4.2 & 1.2 & 28.0 & 3.8 & 1.1 & 27.9 \\
\hline 0.3 & 9.5 & 3.5 & 36.9 & 10.7 & 4.1 & 38.2 & 8.3 & 2.3 & 28.2 & 7.1 & 1.7 & 23.2 & 7.4 & 1.8 & 23.8 & 6.9 & 1.6 & 22.7 \\
\hline 0.4 & 13.9 & 4.1 & 29.1 & 15.4 & 4.4 & 28.8 & 12.5 & 3.1 & 25.2 & 10.5 & 2.4 & 22.7 & 11.2 & 2.4 & 21.3 & 9.9 & 2.3 & 23.1 \\
\hline 0.5 & 19.2 & 5.1 & 26.5 & 21.1 & 5.3 & 25.0 & 17.3 & 4.3 & 24.6 & 15.2 & 3.3 & 21.7 & 16.0 & 3.3 & 20.5 & 14.5 & 3.3 & 22.5 \\
\hline 0.6 & 23.3 & 5.3 & & 25.4 & 5.3 & & & 4.6 & 21.7 & 19.4 & 3.6 & 18.4 & 20.6 & 3.2 & 15.3 & 18.2 & 3.7 & 20.1 \\
\hline 0.7 & 27.3 & 5.9 & 21.4 & 29.8 & 5.3 & 17.9 & 24.9 & 5.4 & 21.8 & 23.8 & 4.0 & 17.0 & 25.2 & 3.1 & 12.4 & 22.4 & 4.5 & 19.9 \\
\hline 0.8 & 31.4 & 5.9 & 18.8 & 34.1 & 5.2 & 15.3 & 28.6 & 5.3 & 18.6 & 27.7 & 4.5 & 16.4 & 29.5 & 3.8 & 13.0 & 26.0 & 4.6 & 17.8 \\
\hline 0.9 & 35.2 & 5.6 & 15.9 & 38.1 & 4.7 & 12.4 & 32.4 & 5.0 & 15.6 & 31.3 & 5.0 & 16.1 & 33.0 & 4.6 & 13.8 & 29.5 & 5.0 & 16.9 \\
\hline 1.0 & 38.9 & 5.4 & 13.8 & 41.6 & 4.6 & 11.0 & 36.2 & 4.9 & 13.5 & 35.0 & 5.2 & 14.9 & 36.7 & 4.9 & 13.2 & 33.4 & 5.2 & 15.5 \\
\hline 1.2 & 45.9 & 5.1 & 11.1 & 48.8 & 4.5 & & 43.0 & & 9.2 & 42.2 & 5.6 & 13.2 & 43.8 & 5.1 & 11.6 & 40.6 & 5.7 & 14.1 \\
\hline 1.4 & 52.9 & 4.9 & 9.3 & 55.2 & 5.2 & 9.4 & 50.6 & 3.5 & 6.9 & 49.3 & 5.3 & 10.8 & 50.7 & 4.8 & 9.5 & 47.9 & 5.6 & 11.6 \\
\hline 1.6 & 58.7 & 4.8 & 8.1 & 60.4 & 5.1 & 8.4 & 57.0 & 3.9 & 6.8 & 55.5 & 5.3 & 9.5 & 56.8 & 5.2 & 9.1 & 54.3 & 5.2 & 9.6 \\
\hline 1.8 & 63.6 & 4.6 & 7.3 & 65.3 & 4.7 & 7.2 & 61.9 & 4.0 & 6.4 & 61.1 & 5.0 & 8.1 & 62.2 & 5.0 & 0 & 59.9 & 4.8 & 8.1 \\
\hline 2.0 & 68.6 & 4.2 & 6.1 & 70.0 & 3.9 & 5.6 & 67.1 & 4.0 & 6.0 & 66.5 & 4.8 & 7.3 & 67.6 & 4.8 & 7.1 & 65.5 & 4.8 & 7.4 \\
\hline 2.5 & 78.0 & 3.8 & 4.9 & 79.4 & 2.9 & 3.6 & 76.6 & 4.2 & 5.5 & 76.7 & 4.2 & 5.5 & 77.8 & 3.6 & 4.6 & 75.7 & 4.6 & 6.1 \\
\hline 3.0 & 85.0 & 3.3 & 3.9 & 86.3 & 1.8 & 2.1 & 83.7 & 4.0 & 4.8 & 84.5 & 3.1 & 3.7 & 85.1 & 2.9 & 3.5 & 83.9 & 3.3 & 3.9 \\
\hline 3.5 & 90.1 & 2.5 & 2.7 & -91.0 & 1.4 & 1.5 & 89.1 & 3.0 & 3.3 & g으.으. & 2.3 & 2.6 & 90.4 & 2.3 & 2.5 & 89.5 & 2.4 & 2.7 \\
\hline 4.0 & $93 . \overline{6}$ & 1.7 & $\overline{9}$ & 94.4 & 1.0 & 1.0 & 92.9 & $\underline{2} .1$ & 2.2 & $93 . \overline{9}$ & 1.8 & 1.9 & 94.0 & 1.8 & 19 & 93.4 & 18. & 1.9 \\
\hline 4.5 & 95.8 & 1.4 & 1.4 & 96.3 & 0.8 & 0.8 & 95.3 & $\overline{1} . \overline{6}$ & 1.7 & 95.9 & 1.5 & 1.6 & 96.1 & 1.5 & 1.5 & 95.7 & 1.5 & 1.6 \\
\hline 5.0 & 97.2 & 1.2 & 1.2 & 97.6 & 0.7 & 0.7 & 96.7 & 1.4 & 1.5 & 97.2 & 1.4 & 1.5 & 97.3 & 1.4 & 1.5 & 97.1 & 1.5 & 1.6 \\
\hline 5.5 & 97.8 & 1.1 & 1.1 & 98.1 & 0.7 & 0.7 & 97.5 & 1.3 & 1.3 & 97.9 & 1.3 & 1.3 & 97.9 & 1.3 & 1.3 & 97.8 & 1.4 & 1.4 \\
\hline 6.0 & 98.1 & 0.9 & 1.0 & 98.3 & 0.6 & 0.6 & 97.8 & 1.1 & 1.2 & 98.1 & 1.1 & 1.1 & 98.2 & 1.1 & 1.1 & 98.1 & 1.2 & 1.2 \\
\hline $\begin{array}{l}\text { Two-way } \\
\text { ANOVA }\end{array}$ & & $\begin{array}{l}\text { gender } \\
\text { sectio } \\
\text { interar }\end{array}$ & $\begin{array}{l}\text { differe } \\
\text { n differ } \\
\text { tion }\end{array}$ & & $\begin{array}{l}\mathrm{F} \text {-value } \\
\mathrm{F} \text {-value } \\
\mathrm{F} \text {-value }\end{array}$ & $\begin{array}{l}=10.94 \\
=4841 \\
=3.20\end{array}$ & & $\begin{array}{l}* \\
* \\
*\end{array}$ & & & $\begin{array}{l}\text { gender } \\
\text { sectio } \\
\text { interad }\end{array}$ & $\begin{array}{l}\text { differ } \\
n \text { diffe } \\
\text { ction }\end{array}$ & $\begin{array}{l}\text { ce } \\
\text { ace }\end{array}$ & $\begin{array}{l}\text { F-value } \\
\text { F-value } \\
\text { F-value }\end{array}$ & $\begin{array}{l}=3.55 \\
=5514.4 \\
=1.58\end{array}$ & & $\begin{array}{l}\mathrm{ns} \\
* \\
*\end{array}$ & \\
\hline
\end{tabular}




\section{Discussion}

This study paid attention to COP periodicity of body sway. The frequency band of the power spectrum of an international standard was established as 3 frequency sections of $0.02-0.2 \mathrm{~Hz}(\mathrm{~A}), 0.2-2.0 \mathrm{~Hz}(\mathrm{~B})$ and $2.0-10.0 \mathrm{~Hz}(\mathrm{C})$ without distinguishing body sway time series and velocity time series, based on Kapteyn's proposal [5], and their relative frequency values have been evaluated. The above-frequency sections may be effective to evaluate the sway of disordered people, showing high power spectra in the specific high frequency band (e.g.; unilateral labyrinth disability: in the X-direction, at about $2 \mathrm{~Hz}$, subfolium disability: at about $3 \mathrm{~Hz}$ ) [5-6]. For the present preschool children, the power of body sway time series and velocity time series appeared under $0.2 \mathrm{~Hz}$ in both directions, and the power spectrum over $2.0 \mathrm{~Hz}(\mathrm{C}: 2 \mathrm{~Hz}-10 \mathrm{~Hz}$ ) was $15 \%$ or less of a total power spectra. In short, it was confirmed that power spectra of preschool children are found in $6.0 \mathrm{~Hz}$ or less (95\% or more), and their characteristics exist mainly in low frequency sections (A and B sections) of an international standard. Frequency bands with a large CV over 10.0 appeared up to $1.5 \mathrm{~Hz}$ in both power spectra of both directions and as the frequency became higher, the CV became less. Gielen and Denier van der Gon JJ [15] also reported that preschool children's sway periodicity belongs to the low frequency band. From the present results, it is considered that the evaluation method based on three sections of the international standard set to evaluate the change of disordered person's high frequency cannot properly evaluate sway periodicity characteristics of preschool children. When evaluating frequency characteristics of body sway, the index used is divided largely into the following 2 types: specific single frequency (ex; mean frequency) and frequencies included in a certain range. Fujiwara and Ikegami [8] reported that using only the former specific frequency may not be effective to wholly evaluate distribution 
characteristics. As adopted also in the international standard, the latter evaluation method will be effective.

From the present results, preschool children's distribution of power spectra are considered to be rather different in both time series and in both directions. However, the international standard uses the same frequency section to evaluate frequency characteristics of time series and velocity time series or right-left and front-back directions without distinguishing them. Therefore, it is judged that preschool children's frequency characteristics cannot be properly evaluated. It will be necessary to establish evaluation frequency sections according to body sway time series and velocity time series. Meanwhile, previous studies [16-17] have mainly examined body-sway characteristics of preschool children in a comparison with those of young adults or the elderly. The following were reported: important brain and nervous system functions for posture maintenance develop markedly [18], the participation at the substantia corticalis level is small and their posture is mainly maintained by the subordinate central nervous system [16], and they have undeveloped spine erector and antagonist muscles (abdominal muscle) related to posture control [12]. In short, it is considered that preschool-aged children are at a marked developmental stage for the important posture adjustment function for posture maintenance, and the work and sway periodic characteristics are very different from those in young adults. In this study, significant gender differences were found in the low frequency bands. Deoreo [19] reported that a gender difference in preschool children from 3 to 5 years was not found in a walking test, but girls are superior in balance ability because of their small body sway in the balance test using the equilibrium board. Williams and James [17] and Fujiwara and Ikegami [8] also reported that the girls are superior in static equilibrium. In addition, preschool children may have a gender difference also in periodical characteristics of 
body sway, as well as physique and physical fitness [13].

In summary, almost all powers of body sway and sway velocity time series of preschool children are found mainly in the low frequency bands (A and B sections) of the international standard, and their frequency characteristics differ in the Medial/Lateral and Anterior/Posterior directions. Gender differences exist in the low frequency band and individual differences are also large. The existing evaluation section of the international standard cannot properly evaluate periodic characteristics of body sway time series and velocity time series of preschool children. 


\section{References}

1. Demura S, Yamaji S, Noda M, Kitabayashi T, Nagasawa Y. (2001) :Examination of Parameters Evaluating the Center of Foot Pressure in Static Standing Posture from Viewpoints of Trial-to-trial Reliability and Interrelationships Among Parameters. Equilibrium Res 60, 44-55.

2. Kitabayashi T, Demura S, Noda M, Imaoka K. (2002) :Gender Differences and Relationships between Physic and Parameters Evaluating the Body Center of Pressure in Static Standing Posture. Equilibrium Res, 61, 16-19.

3. Cernacek J, Jagr J, Harman B, Vyskocil S. (1973) : Stabilographic finding in central vestibular disturbances, Agressologie, 14, 21-26.

4. Aggashyan RV, Gurfinkel VS, Mamasakhlisov GV, Elner AM. (1973) :Changes in spectral and correlation characteristics of human stabilograms at muscle afferentation disturbance.; 14(SpecNoD): 5-9.

5. Kapteyn TS, Bles W., Njiokiktjien CJ. Kodde L, Massen CH, Mol JM. (1983): Standardization in platform stabilometry being a part of posturography. Agressologie, 24, 321-326.

6. Tokita T, Miyata H, Matsuoka T, Taguchi T, Shimada R. (1976) : Correlation analysis of the body sway in standing posture. Agressologie,17 SPECNO, 7-16.

7. Yoneda S, Tokumasu K. (1986): Frequency analysis of body sway in the upright posture. Statistical study in cases of peripheral vestibular disease. Acta Otolaryngol., 102(1-2), 87-92.

8. Fujiwara K, Ikegami H. (1984): Chronological change in frequency component of body sway in up right stance. Jpn.J.Hum.Posture, 2, 81-88.

9. Miyoshi T, Shirato M, Hiwatashi S. (1979): Two phase body sway by optokinetic stimulation. Agressologie, 20(2), 119-125. 
10. Kitabayashi T, Demura S, Noda M. (2003) : Examination of the Factor Structure of Center of Foot Pressure Movement and Cross-validity. J Physiol Anthropol Appl Human Sci, 22(6), 265-272.

11. Liao-CH, Yang-YH, Chiang-BL. (2003): Systemic lupus erythematosus with presentation as vertigo and vertical nystagmus: Report of one case. Acta Paediatrica Taiwanica, 44(3), 158-160.

12. Usui N, Maekawa K, Hirasawa Y. (2001) : Development of the upright postural sway of children. Dev Med Child Neuro, 137, 985-996.

13. Baker CP, Newstead AH, Mossberg KA, Nicodemus CL.(1998): Reliability of static standing balance in nondisabled children: comparison of two methods of measurement. Pediatr Rehabil. Jan-Mar,2(1),15-20.

14. Japan Society for Equilibrium Research. (1994) :A fact of Equilibrium Research, Nanzando, Japan, in Japanese.

15. Gielen CCAM, Denier van der Gon JJ. (1988) : Pos-tural adjustments induced by simulated motion of differentlystructured environments. Exp Brain Res, 73, 371-383.

16. Forssberg, H. (1985): Ontogeny of human locomotorcontrol I. Infant stepping, supported locomotion andtransition to independent locomotion. ExperimentalBrain Research, 57, 480-493.

17. Williams MC, James LF.(1983) :Effects of herbicides on the concentration of poisonous compounds in plants.Am J Vet Res. Dec,44(12),2420-2422.

18. Melzer I, Benjuya N, Kaplanski J. (2001) :Age-related changes of postural control: effect of cognitive tasks. Gerontology, Jul-Aug,47(4), 189-94.

19. Deoreo K. (1971) :Dynamic and Static Balancing Ability of Pre-school, Children. Journal of Motor Behavior,3(4),326-335. 